\title{
Biomarkers for suicidal behavior: miRNAs and their potential for diagnostics through liquid biopsy - a systematic review
}

\author{
Katarina Kouter ${ }^{1}$ (D) \& Alja Videtič Paska*,1 (iD) \\ ${ }^{1}$ University of Ljubljana, Faculty of Medicine, Institute of Biochemistry and Molecular Genetics, Medical Centre for Molecular \\ Biology, Vrazov trg 2, SI-1000 Ljubljana, Slovenia \\ *Author for correspondence: alja.videtic@mf.uni-lj.si
}

Background: Given that approximately $70 \%$ of miRNAs in the body are neuronal, we critically assessed current studies on miRNAs and suicidal behavior. Materials \& Methods: To further define the role of miRNAs in suicide, we searched for studies on extracellular vesicles (exosomes) because miRNAs are particularly enriched in exosomes. miRNAs also have important physiological roles, and they can cross the blood-brain barrier and participate in cell-to-cell communication with both nearby and distant cells. Results \& Conclusion: This critical assessment suggests that several miRNAs can be closely related to neurophysiology, suicidal behavior, and psychiatric disorders. However, clear overlap is poor due to either different methodologies applied or to molecular differences between suicidal behaviors and studied psychiatric disorders.

First draft submitted: 15 May 2020; Accepted for publication: 4 October 2020; Published online: 22 December 2020

Keywords: exosome • extracellular vesicle • miRNA • noncoding RNA • psychiatric disorder • suicide

Suicide is a major, but preventable, mental health issue. Estimates indicate that every year, approximately 800,000 people worldwide die due to suicide. This equates to a global suicide rate (i.e., number of suicides $/ 100,000$ people) of 10.5 (13.7 for males and 7.5 for females) [1]. Despite the significant impact that suicide and suicidal behavior have on society and the increasing awareness of society, the overall understanding of this phenomenon remains limited. Because of the complexity and multifactorial nature of suicidal behavior, it cannot be attributed to only one risk factor; instead, it is an interplay of several factors, ranging from sociodemographic, to environmental factors, to biological factors such as genetics [2]. Among the environmental and social factors, the most important are loneliness, being a widow(er), and stressful circumstances; among biological factors, most suicides can be attributed to a family history of suicidal behavior $[3,4]$. The risk for suicidal behavior is particularly elevated in people who have already attempted suicide and in those who suffer from mood disorders, most often as depressive disorders, alcohol dependency syndrome, and certain personality traits such as impulsive and aggressive behavior [5,6]. The risk for suicidal behavior is markedly increased when factors that act independently of each other intertwine.

Viewed through a particular phenotype or even more defined endophenotype, it appears that genetic background has an even more relevant role in suicidal behavior than was initially thought. On the basis of accumulating data on family [7-11], twin [12] and adoption [13] studies, it has been estimated that about one-third of suicide risk can be explained by genetics [4,5]. After the first study on the molecular background of suicidal behavior by Asberg et al. (1976), where lower levels of the serotonin (also known as 5-hydroxytryptamine [5-HT]) degradation metabolite 5-hydroxyindolacetic acid in cerebrospinal fluid were associated with violent suicide [14], the research into the molecular genetics background of suicidal behavior widened.

Over recent decades, the majority of the molecular biology studies on suicidal behavior (i.e., suicide attempts, completed suicides) and suicidal ideation have focused on the coding regions of DNA, where different polymorphisms have been investigated across a panel of candidate genes. These genes were first selected from among those that code proteins that are involved in neurotransmitter signaling, and particularly in the serotonergic, dopaminergic, and noradrenergic systems [5]. Later, this was expanded to include other genes, such as BDNF, the GABA 
receptor, $C K K, S A T 1$ [15] and others that have significant roles in brain biology. A comprehensive up-to-date view of the history of the genetics of suicidal behavior was captured by Andriessen and Videtič Paska [16].

However, it is now clear that no single gene can be said to underlie suicide; rather, we are well aware that multiple genes and their variations (i.e., polymorphisms) with small effect sizes contribute to the final development of the suicidal phenotype. Given that individual environmental and genetic factors have such important roles in suicide, it is important to investigate these together. The common linkage of these two areas might be epigenetics. Among the epigenetic mechanisms are DNA methylation, the presence of different histone variants and posttranslational modifications, along with regulatory noncoding RNAs (ncRNAs) [17].

In humans, many ncRNAs are known, as there are more than 3000 genes that encode them. ncRNAs participate in protein biosynthesis and mRNA maturation, and they are associated with different diseases. ncRNAs can be divided into several groups, including miRNAs, Piwi RNAs and long noncoding RNAs. miRNAs are singlestranded RNA molecules that are 19-25 base-pairs long, and they bind to $3^{\prime}$-untranslated regions (3'UTRs) of genes to prevent transcription [18]. In silico predictions show that more than $60 \%$ of protein-coding genes appear to be the targets of miRNAs [19]. Recently, according to miRBbase.org, there were 1917 annotated hairpin precursors, and 2654 mature miRNA sequences indicated [20].

Also recently, it was shown that miRNAs are particularly enriched in exosomes, which are extracellular vesicles that are secreted by almost all cells in the body. Exosomes can cross the blood-brain barrier and can be internalized by recipient cells, where the miRNA cargo can affect cell transcription [21]. The miRNAs in the CNS account for approximately $70 \%$ of the total miRNAs in the human body, and these have roles in the regulation of neurogenesis and neuroplasticity [22], which have both been shown to undergo important changes in suicidal behavior and psychiatric disorders [23]. Therefore, with their packing into exosomes, miRNAs appear to be important players in psychiatric disorders. Moreover, due to the presence of exosomes in the blood, miRNAs might also represent easily available biomarkers.

To the best of our knowledge, there have been no systematic reviews to date on miRNAs and exosomes in suicidal behavior or on how miRNAs identified in suicidal behavior might overlap with miRNAs identified in psychiatric disorders. The main goal of the present systematic review was to synthesize the studies that have investigated miRNAs in the CNS and in the periphery to identify potential biomarkers that can be tested in a clinical environment. These might complement current approaches in diagnosis, monitoring and treatment of patients with suicidal behavior in the era of personalized medicine.

\section{Methods}

This systematic review was prepared according to the Preferred Reporting Items for Systematic Reviews and Meta-Analyses (PRISMA) guidelines for systematic reviews [24].

\section{Literature search strategy}

Literature searches were performed in PubMed, including all papers published up to March 2020. The searches were limited to the English language, as full-text publications, with no further date restrictions. They were conducted using keywords, asterisks (i.e., * as an indication of truncated versions of words) and Boolean operators. The search terms used were (i) "microRNA OR miRNA AND suicid*"; and (ii) "suicid* OR depressi* OR schizophren* OR bipolar disorder AND exosom* OR extracellular vesicle*”. For additional hits, review paper bibliographies were also checked.

\section{Study selection: inclusion \& exclusion criteria}

First, the titles and abstracts of all of the papers initially identified were screened. The inclusion criteria were as follows: original research studies that included suicide victims or patients who showed suicidal behavior, inclusion of an appropriate placebo or control group and analysis of at least one miRNA; and original research studies on suicidal behavior or depression or schizophrenia (SZ) and exosomes with inclusion of an appropriate placebo or control group, as well as analysis of at least one miRNA. These were defined regardless of subject age, gender or additional diagnosis. The exclusion criteria were as follows: studies not reporting original research, studies that examined nonsuicidal nonpsychiatric research (e.g., mostly oncology and suicide gene cancer therapy), studies that examined nonsuicidal psychiatric research, studies that did not report original research and studies that examined nonpsychiatric research (e.g., mostly oncology and neurotransmission) and animal studies. 

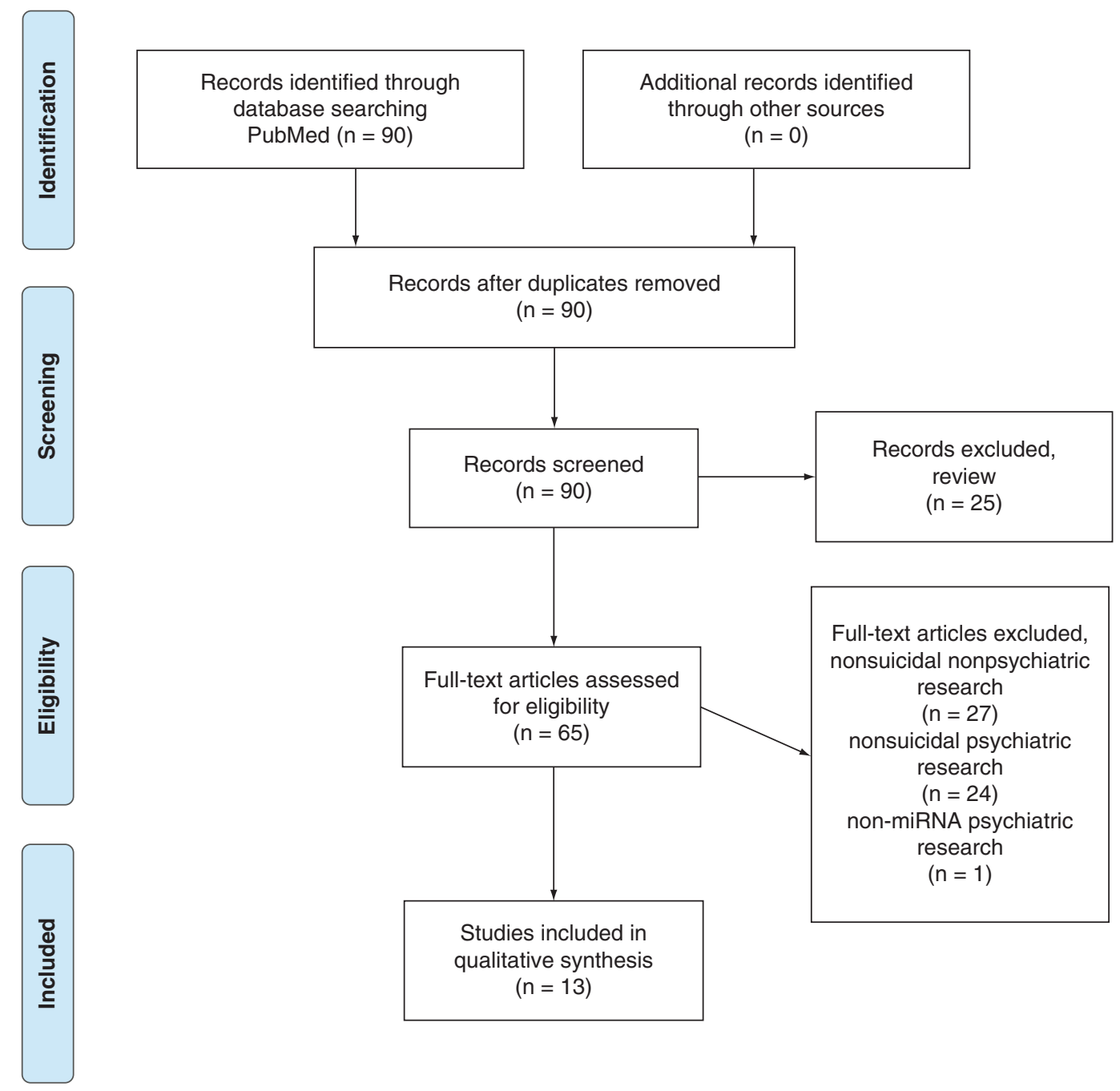

Full-text articles excluded, nonsuicidal nonpsychiatric research $(\mathrm{n}=27)$

nonsuicidal psychiatric research $(n=24)$

non-miRNA psychiatric research $(n=1)$

Figure 1. Flow chart of the selection of studies on miRNAs and suicidal behavior. Only original research papers indexed by PubMed that have investigated miRNAs in suicidal behavior were included in the final selection. Adapted from [24].

\section{Analysis \& data synthesis}

The final selection of studies was reviewed in detail. The extracted information included author and year of publication, study subjects, type and gender; number of study subjects; sample tissue; research design and methods; miRNA(s) identified; and predicted target gene(s) or pathway(s). Due to the limited amount of studies available and the various methodologies used, a meta-analysis was not conducted.

\section{Quality rating}

The methodological quality of the studies included was assessed using the Mixed Methods Appraisal Tool (MMAT) [25]. Studies were divided into the category of quantitative randomized controlled trials and quantitative nonrandomized studies, and they were critically appraised using the MMAT methodological quality criteria questionnaire.

\section{Results}

\section{Study selection \& characterization}

miRNAs \& suicidal behavior

The PubMed search that used the search terms "microRNA OR miRNA AND suicid*" returned 90 hits that were written in English and indexed before March 2020. After careful consideration, 13 research papers that investigated 
miRNAs and suicidal behavior were retained (see flow chart and selection process in Figure 1). The characteristics of each study are summarized in Table 1. These studies were published between 2012 and 2019, with sample sizes from 13 [26] to 237 [27] subjects. The majority of these studies included both male and female subjects, with the exception of three studies that included only men [26,28,29]. A large number of these studies focused on miRNA expression in the prefrontal cortex [28-36]. Seven of these studies analyzed preselected candidate genes using quantitative real-time PCR (RT-qPCR) methods [26,28-33]. Other studies analyzed miRNA expression across the genome, using either small RNA-sequencing (RNA-seq) approaches [27,34,35] or TaqMan RT-qPCR low-density array (TLDA)-based miRNA profile approaches [29,36-38].

miRNAs in extracellular vesicles \& schizophrenia, bipolar disorder \& depression

The PubMed search that used the search terms "suicid* OR depressi* OR schizophren* OR bipolar disorder AND extracellular vesicle" returned 135 hits and the search terms "suicid* OR depressi* OR schizophren* OR bipolar disorder AND exosom*" returned 52 hits that were written in English and indexed before April 2020. After careful consideration, seven research studies that investigated miRNAs and SZ or bipolar disorder (BD) were retained (see flow chart selection and selection process in Figure 2). However, of these seven studies, two were duplicates, and so five studies were considered in the further analysis. The characteristics of each study are summarized in Table 2. After careful revision of review papers, an additional study on exosomal miRNAs and depression [39] that was not indexed in PubMed was added. These studies were published between 2013 and 2020, with sample sizes from 1 [39] to 295 [40] subjects. The majority of these studies included both male and female subjects, with the exception of two studies that included predominantly men ( 83\% [41], $\sim 73 \%[42])$, and one with no data on the subject sexes included [39]. In two of these studies, extracellular vesicles were isolated from the mixed prefrontal cortex of the left and right hemispheres [41,42], in two they were isolated from peripheral blood serum [39,40], and in two from peripheral blood plasma [43,44]. Four of these studies used genome-wide approaches, using either small RNA-seq or extensive predesigned gene panels [39,40,43,44], and two of these studies included only a candidate gene approach using RT-qPCR [41,42].

Only original research studies indexed by PubMed or identified in other review papers that investigated miRNAs and listed the psychiatric disorders were included in the final selection.

\section{Study quality rating \\ miRNAs \& suicidal behavior}

Using MMAT, we classified one study as a quantitative randomized controlled trial [27], and 11 studies as quantitative nonrandomized studies [26,28-31,33-38]. One study included both a randomized controlled trial part and a quantitative nonrandomized study part [32]. Although the studies included were of good quality, some discrepancies were observed. The randomized controlled trial studies were double-blinded, but they lacked detailed information regarding the randomization schedule $[27,32]$.

For nonrandomized studies, two studies had a large difference in age between the studied groups (suicide victims, $45.22 \pm 14.78$ years vs control group, $66.90 \pm 13.88$ years; suicide victims, $40.0 \pm 8.7$ years vs control group, $51.8 \pm 6.5$ years) $[26,37]$. The first of these two studies reported that there were no significant effects of age on the miRNA expression data when correlated with this confounding variable [37], whereas the second did not appear to account for this confounder in their statistical analysis [26]. Two studies lacked the information to determine whether the subjects represented the target population; the first of these used a previously described brain collection (i.e., the Stanley Neuropathology Consortium) but did not give the detailed data in the paper [38]. The second study here had missing information on gender and age of the post-mortem study subjects [32].

\section{miRNAs in extracellular vesicles \& schizophrenia, bipolar disorder \& depression}

Using MMAT, we classified all of the studies that were quantitative nonrandomized studies. Although these studies were of good quality, some discrepancies were observed. One study had a statistically significant difference in age between the studied groups (euthymia $37.8 \pm 10.8$ years vs mania $33.7 \pm 10.7$ years vs depression $40.3 \pm 8.1$ years vs control subjects $30.7 \pm 8.1$ years), although this study included statistical adjustment for age [43]. One study did not calculate the mean ages and standard deviation between the groups [42], and for another study, no data on age were given [39]; neither of these studies appeared to account for this confounder in their statistical analyses. Two studies lacked the information on clinical interviews to determine whether the subjects represented the target population [41,42], but they used samples from the brain collection BrainNet Europe II, McLean 66 Cohort 
Table 1. Studies of miRNAs and suicidal behavior.

\begin{tabular}{|c|c|c|c|c|c|c|}
\hline Study (year) & Study subjects & $n$ & Target & Method & Identified miRNA & $\begin{array}{l}\text { Predicted target gene or } \\
\text { pathway }\end{array}$ \\
\hline \multirow{2}{*}{$\begin{array}{l}\text { Gorinski } \\
\text { et al. (2019) }\end{array}$} & MDD suicide victims & 16 & \multirow{2}{*}{$\begin{array}{l}\text { Dorsal lateral } \\
\text { prefrontal cortex (BA9) }\end{array}$} & \multirow{2}{*}{$\begin{array}{l}\text { Candidate gene } \\
\text { analysis: RT-qPCR }\end{array}$} & \multirow[t]{2}{*}{$\operatorname{miR}-30 \mathrm{e} \uparrow$} & \multirow[t]{2}{*}{$Z D H H C 21$} \\
\hline & $\begin{array}{l}\text { Nonpsychiatric control } \\
\text { subjects }\end{array}$ & 16 & & & & \\
\hline \multirow[t]{2}{*}{$\begin{array}{l}\text { Belzeaux } \\
\text { et al. (2019) }\end{array}$} & $\begin{array}{l}\text { MDD patients \& } \\
\text { duloxetine }\end{array}$ & 112 & \multirow[t]{2}{*}{ Whole blood } & \multirow{2}{*}{$\begin{array}{l}\text { Genome wide } \\
\text { analysis: small } \\
\text { RNA-seq }\end{array}$} & \multirow[t]{2}{*}{$\operatorname{miR}-3688 \uparrow, \operatorname{miR}-5695 \uparrow$} & \multirow{2}{*}{$\begin{array}{l}\text { Gene ontology leading to } \\
\text { "regulation of } \\
\text { neurogenesis" }\end{array}$} \\
\hline & $\begin{array}{l}\text { MDD patients \& } \\
\text { placebo }\end{array}$ & 125 & & & & \\
\hline \multirow[t]{8}{*}{ Wang et al. (2018) } & MDD suicide & 21 & \multirow{3}{*}{$\begin{array}{l}\text { Dorsolateral prefrontal } \\
\text { cortex (BA10) }\end{array}$} & \multirow{8}{*}{$\begin{array}{l}\text { Candidate gene } \\
\text { analysis: RT-qPCR }\end{array}$} & \multirow[t]{8}{*}{$\operatorname{miR}-19 a-3 p \uparrow$} & \multirow[t]{8}{*}{ Proinflammation; $T N F-\alpha$} \\
\hline & $\begin{array}{l}\text { Suicide victims \& other } \\
\text { psychiatric disorders }\end{array}$ & 22 & & & & \\
\hline & $\begin{array}{l}\text { Nonpsychiatric control } \\
\text { subjects }\end{array}$ & 16 & & & & \\
\hline & MDD suicide victims & 14 & \multirow{3}{*}{$\begin{array}{l}\text { Dorsolateral prefrontal } \\
\text { cortex (BA10) }\end{array}$} & & & \\
\hline & $\begin{array}{l}\text { MDD nonsuicide } \\
\text { subjects }\end{array}$ & 12 & & & & \\
\hline & $\begin{array}{l}\text { Healthy control } \\
\text { subjects }\end{array}$ & 12 & & & & \\
\hline & $\begin{array}{l}\text { MDD patients + } \\
\text { suicidal ideation }\end{array}$ & 12 & \multirow[t]{2}{*}{ Peripheral blood } & & & \\
\hline & $\begin{array}{l}\text { Healthy control } \\
\text { subjects }\end{array}$ & 12 & & & & \\
\hline \multirow[t]{2}{*}{ Roy et al. (2017) } & MDD suicide victims & 9 & \multirow[t]{2}{*}{ Locus coeruleus } & \multirow{2}{*}{$\begin{array}{l}\text { Genome-wide } \\
\text { analysis: TLDA-based } \\
\text { miRNA profiler }\end{array}$} & \multirow[b]{2}{*}{$\begin{array}{l}\text { miR-17-5p, miR-20b-5p, } \\
\text { miR-106a-5p, miR-330-3p, } \\
\text { miR-541-3p, miR-582-5p, } \\
\text { miR-890, miR-99b-3p, } \\
\text { miR-550-5p, miR-1179, all } \\
\uparrow ; \text { miR-409-5p, let-7g-3p, } \\
\text { miR-1197, all } \downarrow\end{array}$} & \multirow{2}{*}{$\begin{array}{l}\text { Multiple genes involved in } \\
\text { neurotransmission, } \\
\text { associated with psychiatric } \\
\text { disorders }\end{array}$} \\
\hline & $\begin{array}{l}\text { Healthy control } \\
\text { subjects }\end{array}$ & 11 & & & & \\
\hline \multirow[t]{2}{*}{ Lopez et al. (2017) } & MDD suicide victims & 32 & \multirow{2}{*}{$\begin{array}{l}\text { Ventrolateral } \\
\text { prefrontal cortex }\end{array}$} & \multirow{2}{*}{$\begin{array}{l}\text { Candidate gene } \\
\text { analysis: RT-qPCR }\end{array}$} & \multirow{2}{*}{$\begin{array}{l}\operatorname{miR}-146 a-5 p \\
\text { miR-146b-5p, miR-24-3p, } \\
\text { miR-425-3p, all } \uparrow\end{array}$} & \multirow{2}{*}{$\begin{array}{l}\text { MAPK, Wnt, calcium, } \\
\text { endocytosis and adherens } \\
\text { junction signaling } \\
\text { pathways }\end{array}$} \\
\hline & $\begin{array}{l}\text { Healthy control } \\
\text { subjects }\end{array}$ & 20 & & & & \\
\hline \multirow{4}{*}{$\begin{array}{l}\text { Torres-Berrio } \\
\text { et al. (2017) }\end{array}$} & MDD suicide victims & 24 & \multirow{2}{*}{$\begin{array}{l}\text { Prefrontal cortex } \\
\text { (BA44) }\end{array}$} & Candidate gene & $\operatorname{miR}-218 \downarrow$ & $D C C$ \\
\hline & Control subjects & 35 & & analysis: RT-qPCR & & \\
\hline & MDD suicide victims & 11 & Prefrontal cortex & & & \\
\hline & Control subjects & 12 & (BA44) & & & \\
\hline Pantazatos & MDD suicide victims & 9 & Dorsal lateral & Genome wide & None & None \\
\hline et al. (2017) & $\begin{array}{l}\text { MDD nonsuicide } \\
\text { subjects }\end{array}$ & 9 & prefrontal cortex (BA9) & $\begin{array}{l}\text { analysis: small } \\
\text { RNA-seq }\end{array}$ & & \\
\hline & $\begin{array}{l}\text { Healthy control } \\
\text { subjects }\end{array}$ & 9 & & & & \\
\hline Aschrafi & MDD suicide victims & 5 & Edinger-Westphal & Candidate gene & miR-326 & UCN1 \\
\hline et al. (2016) & Control subjects & 8 & nucleus & analysis: RT-qPCR & & \\
\hline Pantazatos & MDD suicide victims & 9 & Dorsal lateral & Genome wide & None & SAT1 \\
\hline et al. (2015) & $\begin{array}{l}\text { MDD nonsuicide } \\
\text { subjects }\end{array}$ & 9 & prefrontal cortex (BA9) & $\begin{array}{l}\text { analysis: small } \\
\text { RNA-seq }\end{array}$ & & \\
\hline & $\begin{array}{l}\text { Healthy control } \\
\text { subjects }\end{array}$ & 9 & & & & \\
\hline $\begin{array}{l}\text { Smalheiser } \\
\text { et al. (2014) }\end{array}$ & Suicide victims & $\begin{array}{l}18 \text { (7 MDD, } 3 \\
\mathrm{SZ}, 8 \mathrm{BP})\end{array}$ & $\begin{array}{l}\text { Prefrontal cortex } \\
\text { (BA10) }\end{array}$ & $\begin{array}{l}\text { Genome wide } \\
\text { analysis: TLDA-based }\end{array}$ & $\begin{array}{l}\text { miR-152, miR-181a, } \\
\text { miR-330-3p, miR-34a, }\end{array}$ & None stated \\
\hline & Control subjects & $\begin{array}{l}40 \text { (8 MDD, } \\
11 \mathrm{SZ}, 6 \mathrm{BP})\end{array}$ & & miRNA profiler & $\begin{array}{l}\text { miR-133b, miR-224, all } \downarrow \text {; } \\
\text { miR-376a, miR-625, both } \uparrow\end{array}$ & \\
\hline & $\begin{array}{l}\text { Nonpsychiatric control } \\
\text { subjects }\end{array}$ & 15 & & & & \\
\hline Lopez et al. (2014) & MDD suicide victims & 15 & Prefrontal cortex & Candidate gene & miR-34c-5p, miR-139-5p, & SAT1, SMOX \\
\hline & $\begin{array}{l}\text { Healthy control } \\
\text { subjects }\end{array}$ & 16 & (BA44) & analysis: RT-qPCR & miR-195, miR-320c, all $\uparrow$ & \\
\hline
\end{tabular}




\begin{tabular}{|c|c|c|c|c|c|c|}
\hline Study (year) & Study subjects & $\mathbf{n}$ & Target & Method & Identified miRNA & $\begin{array}{l}\text { Predicted target gene or } \\
\text { pathway }\end{array}$ \\
\hline \multirow[t]{4}{*}{$\begin{array}{l}\text { Maussion } \\
\text { et al. (2012) }\end{array}$} & $\begin{array}{l}\text { Low TrkB-T1 expression } \\
\text { suicide victims }\end{array}$ & 4 & \multirow[t]{2}{*}{$\begin{array}{l}\text { Prefrontal cortex } \\
\text { (BA10) }\end{array}$} & \multirow{2}{*}{$\begin{array}{l}\text { Genome wide } \\
\text { analysis: LNA-based } \\
\text { miRNA profiler }\end{array}$} & \multirow[t]{4}{*}{$\operatorname{miR}-185^{*} \uparrow$} & \multirow[t]{4}{*}{ TrkB-T1 } \\
\hline & Normal control subjects & 4 & & & & \\
\hline & Suicide victims & 38 & $\begin{array}{l}\text { Prefrontal cortex } \\
\text { (BA10) }\end{array}$ & \multirow[t]{2}{*}{$\begin{array}{l}\text { Candidate gene } \\
\text { analysis: RT-qPCR }\end{array}$} & & \\
\hline & Control subjects & 17 & & & & \\
\hline \multirow[t]{2}{*}{$\begin{array}{l}\text { Smalheiser } \\
\text { et al. (2012) }\end{array}$} & $\begin{array}{l}\text { Antidepressant-free } \\
\text { MDD suicide victims }\end{array}$ & 18 & \multirow[t]{2}{*}{ Prefrontal cortex (BA9) } & \multirow{2}{*}{$\begin{array}{l}\text { Genome wide } \\
\text { analysis: TLDA-based } \\
\text { miRNA profiler }\end{array}$} & \multirow[b]{2}{*}{$\begin{array}{l}\text { miR-142-5p, miR-137, } \\
\text { miR-489, miR-148b, } \\
\text { miR-101, miR-324-5p, } \\
\text { miR-301a, miR-146a, } \\
\text { miR-335, miR-494, } \\
\text { miR-20b, miR-376a*, } \\
\text { miR-190, miR-155, } \\
\text { miR-660, miR-130a, } \\
\text { miR-27a, miR-497, } \\
\text { miR-10a, miR-20a, } \\
\text { miR-142-3p, all } \downarrow\end{array}$} & \multirow{2}{*}{$\begin{array}{l}\text { Transcription factors and } \\
\text { other nuclear proteins, } \\
\text { transmembrane and } \\
\text { signaling proteins }\end{array}$} \\
\hline & $\begin{array}{l}\text { Nonpsychiatric control } \\
\text { subjects }\end{array}$ & 17 & & & & \\
\hline
\end{tabular}

BA: Brodmann area; BP: Bipolar disorder; LNA: Locked nucleic acids; MDD: Major depressive disorder; RNA-seq: RNA-sequencing; RT-qPCR: Quantitative real-time PCR; SZ: Schizophrenia; TLDA: TaqMan RT-qPCR low-density array.

Collection at Harvard Brain Tissue Resource Center, and Banigan et al. [41] also used samples from the autopsy service at Boston Medical Center (MA, USA). All but one of the studies [42] provided data on medication.

\section{Study results synthesis}

miRNAs \& suicidal behavior

The first published study that examined the role of miRNAs in suicidal behavior compared expression of miRNAs between antidepressant-free depressed suicide victims and nonpsychiatric control subjects. Globally, downregulation of miRNA expression was observed in the suicide victims compared with the control group, with 21 miRNAs showing significant decreases. These miRNAs targeted genes involved in cellular growth and differentiation, various transcription factors, and nuclear proteins, including genes previously associated with depression (e.g., VEGFA). Additional analysis revealed a tightly connected network of 29 miRNAs that were correlated pairwise only in suicide victims (including miRNAs previously associated with SZ, neurite growth and dendritic spine growth). Multiple factors could explain the observed results, but the authors excluded miRNA processing because the analysis of enzymes involved in miRNA processing did not show changes in expression between the two groups [36]. A decrease in miRNA expression was later confirmed by the same group. Eight miRNAs differed significantly between the suicide victims with psychiatric disorders compared with a mixed group (i.e., nonpsychiatric control subjects and patients with psychiatric disorders who died from causes unrelated to suicide). Six miRNAs were downregulated (miR-152, miR-181a, miR-330-3p, miR-34a, miR-133b, miR-224), and two were upregulated (miR-376a, miR625). Interestingly, the most significantly expressed miRNA in this study (miR-152) failed to achieve significance in a previous study [38].

Neurotropic factors are crucial for maintenance of plasticity, growth and differentiation of the brain, which makes them important players in psychopathologies. For example, downregulation of TrkB-T1, a BDNF receptor that lacks the tyrosine kinase domain, had already been associated with suicidal behavior. Changes in TrkB1-T1 expression could be partially explained with epigenetic regulation, such as DNA methylation and histone modifications, although the complete mechanism was not defined. A comparison of suicide victims with known downregulation of TrkB-T1 and a control group identified one miRNA (miR-185*) that was significantly upregulated in the frontal cortex of suicide victims, with five in silico-determined binding sites on TrkB1-T1. These findings were confirmed on an additional independent sample of suicide victims and a control group with unknown TrkB1-T1 expression levels. Similarly, suicide victims had decreased levels of TrkB1-T1 expression and upregulated miR-185*. Finally, in vitro experiments using cell lines further confirmed that miR-185* can regulate TrkB-T1 expression [29]. Another important regulator of brain plasticity is seen by the netrins and their receptor, DCC, which regulates axon growth and helps to maintain fine neuronal connectivity. $D C C$ has already been associated with psychopathology susceptibility, as it has been reported as upregulated in suicide victims. In silico analysis identified miR-128 as a 

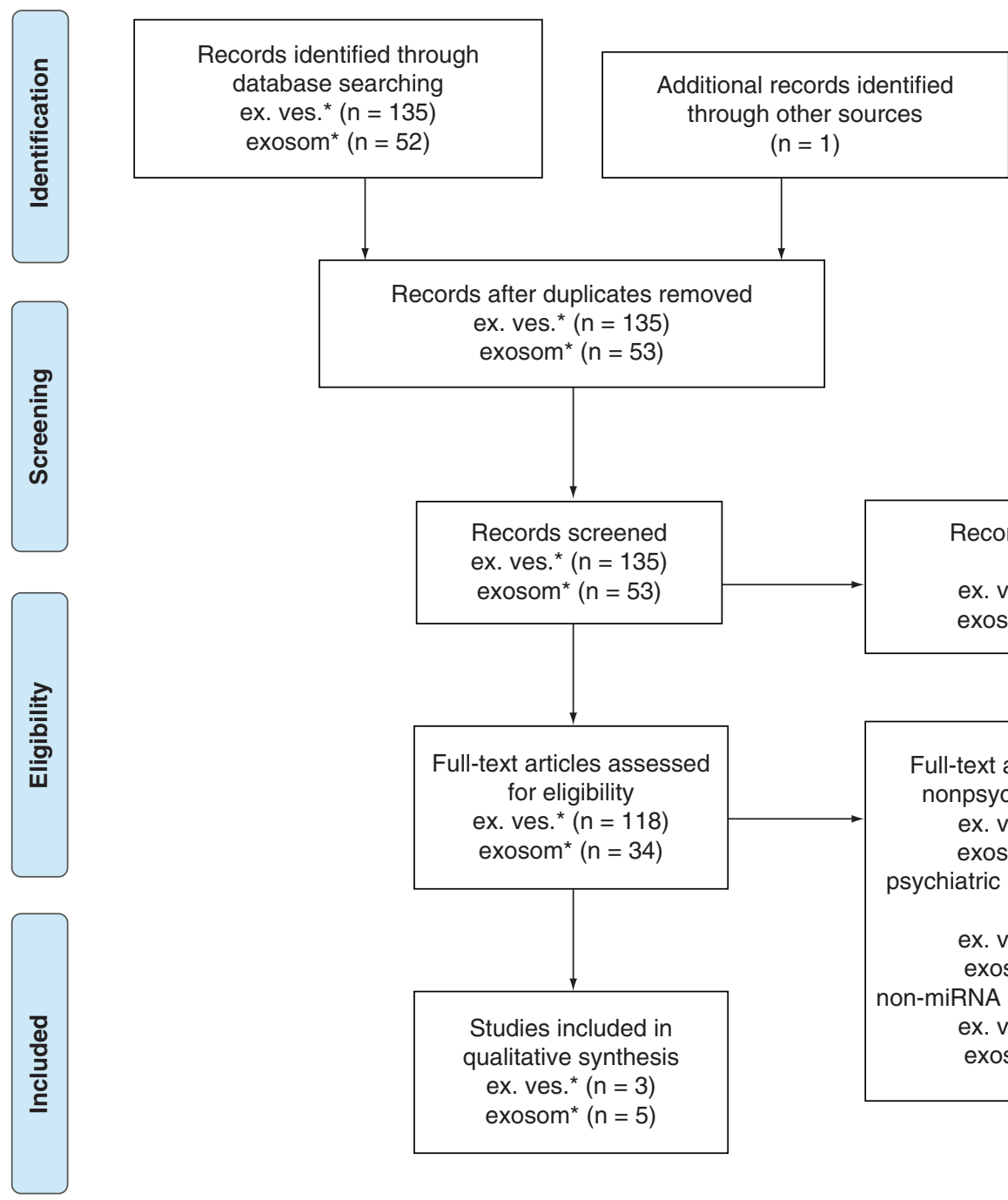

Records excluded, review

ex. ves. * $(n=17)$

exosom* $(n=19)$

Studies included in

ualitative synthesis

.

Full-text articles excluded:

nonpsychiatric research

ex. ves. * $(n=75)$

exosom* $^{*}(n=14)$

psychiatric research on animal models

ex. ves. ${ }^{*}(n=20)$

exosom* $^{*}(n=8)$

non-miRNA psychiatric research

ex. ves. ${ }^{*}(n=20)$

exosom $^{*}(n=7)$

Figure 2. Flow chart of miRNAs, extracellular vesicles or exosomes, and the suicidal behavior, schizophrenia, depression or bipolar disorder study selection. Only original research papers indexed by PubMed or papers identified in other review papers that have investigated miRNAs and the listed psychiatric disorders were included in the final selection.

Ex. ves.: Extracellular vesicles.

Adapted from [24].

potential regulator of $D C C$. As predicted, $D C C$ levels were upregulated in the prefrontal cortex of depressed suicide victims, whereas miR-128 was downregulated. Additionally, negative correlations were seen between the expression of $D C C$ and miR-128 in two cohorts of subjects. These data have been confirmed in depression-susceptible mice, and an in vitro study on human neuroblastoma cells confirmed that miR-128 regulates DCC expression [33].

Stress can greatly increase the risk for suicidal behavior, which makes this behavior a stress-related disorder. UCN1 is a member of the corticotrophin-releasing factor protein family, which is greatly involved in stress responses. UCN1 belongs to a group of neuropeptides, which are molecules that are crucial for maintenance of interneuron communication. Changed levels of UCN1 and its in silico-determined regulatory miR-326 were reported for the Edinger-Westphal nucleus of depressed suicide victims. Suicide victims showed lower levels of miR-326 and upregulation of UCN1. Similar data have been reported for a rat stress model and in vitro [26]. Because the Edinger-Westphal nucleus is one of the projections into the amygdala and lateral hypothalamic area, these data appear to fit within the stress-vulnerability model of suicidal behavior.

Polyamines are molecules that include more than two amino groups. They form the polyamine system, which is involved in numerous cell processes, such as cell growth and ion-channel modulation. Two of the polyamine 
Table 2. Studies of exosomal miRNAs in schizophrenia, bipolar disorder and depression.

\begin{tabular}{|c|c|c|c|c|c|c|c|}
\hline Study (year) & Study subjects & $n$ & Tissue & Type of vesicle & Method & $\begin{array}{l}\text { Studied/identified } \\
\text { miRNA }\end{array}$ & $\begin{array}{l}\text { Predicted target gene or } \\
\text { pathway }\end{array}$ \\
\hline $\begin{array}{l}\text { Banigan } \\
\text { et al. (2013) }\end{array}$ & Bipolar disorder & 9 & $\begin{array}{l}\text { Prefrontal cortex } \\
\text { (BA9) }\end{array}$ & Exosomes & $\begin{array}{l}\text { Candidate gene } \\
\text { analysis: Luminex, } \\
\text { RT-qPCR }\end{array}$ & $\begin{array}{l}\text { Bipolar disorder: } \\
\text { miR-29c^, schizophrenia: } \\
\text { miR-497 } \uparrow\end{array}$ & $\begin{array}{l}\text { Wnt signaling, } \\
\text { pathogenesis of } \\
\text { neoplasms, } \\
\text { neurodegenerative } \\
\text { diseases and heart disease }\end{array}$ \\
\hline \multirow[t]{3}{*}{ Du et al. (2019) } & $\begin{array}{l}\text { Schizophrenia, } \\
\text { first episode }\end{array}$ & 49 & $\begin{array}{l}\text { Peripheral blood } \\
\text { serum }\end{array}$ & \multirow[t]{3}{*}{ Exosomes } & \multirow{3}{*}{$\begin{array}{l}\text { Genome-wide } \\
\text { analysis: small } \\
\text { RNA-seq }\end{array}$} & \multirow[t]{3}{*}{$\begin{array}{l}\text { miR-206, miR-619-5p, } \\
\text { both } \uparrow, \text { has-miR-144-3p } \downarrow\end{array}$} & \multirow{3}{*}{$\begin{array}{l}\text { Protein glycosylation, } \\
\text { neurotransmitter receptor } \\
\text { and dendrite (spine) } \\
\text { development, BDNF }\end{array}$} \\
\hline & Schizophrenia & 100 & \multirow{2}{*}{$\begin{array}{l}\text { Candidate gene } \\
\text { analysis: RT-qPCR }\end{array}$} & & & & \\
\hline & $\begin{array}{l}\text { Nonpsychiatric } \\
\text { control }\end{array}$ & 100 & & & & & \\
\hline \multirow{2}{*}{$\begin{array}{l}\text { Choi } \\
\text { et al. (2016) }\end{array}$} & Bipolar disorder & 5 & \multirow[b]{2}{*}{$\begin{array}{l}\text { Anterior cingulate } \\
\text { cortex tissue } \\
\text { (BA24); laser } \\
\text { capture } \\
\text { micro-dissection } \\
\text { of BA24 cortical } \\
\text { neurons and glia }\end{array}$} & \multirow{2}{*}{$\begin{array}{l}\text { Extracellular } \\
\text { vesicles }\end{array}$} & \multirow{2}{*}{$\begin{array}{l}\text { Candidate gene } \\
\text { analysis: RT-qPCR }\end{array}$} & \multirow{2}{*}{$\begin{array}{l}\text { miR-149 } \uparrow ; \text { miR-29c, } \\
\text { miR-31, miR-15b, } \\
\text { miR-497, miR-219 }\end{array}$} & \multirow{2}{*}{$\begin{array}{l}\text { Regulating cell } \\
\text { differentiation and cell } \\
\text { death, neuropathology }\end{array}$} \\
\hline & $\begin{array}{l}\text { Nonpsychiatric } \\
\text { control }\end{array}$ & 6 & & & & & \\
\hline \multirow{2}{*}{$\begin{array}{l}\text { Fries } \\
\text { et al. (2019) }\end{array}$} & Bipolar disorder & 20 & \multirow{2}{*}{$\begin{array}{l}\text { Peripheral blood } \\
\text { plasma }\end{array}$} & \multirow{2}{*}{$\begin{array}{l}\text { Extracellular } \\
\text { vesicles }\end{array}$} & \multirow{2}{*}{$\begin{array}{l}\text { Genome wide: } \\
\text { Human miRNA } \\
\text { Release } 21 \\
\text { Microarray kits }\end{array}$} & \multirow{2}{*}{$\begin{array}{l}33 \text { nominally significant } \\
\text { miRNAs }\end{array}$} & \multirow{2}{*}{$\begin{array}{l}\text { Axon guidance by netrin } \\
\text { and the serotonin } \\
\text { receptor pathway }\end{array}$} \\
\hline & $\begin{array}{l}\text { Nonpsychiatric } \\
\text { control }\end{array}$ & 21 & & & & & \\
\hline \multirow{2}{*}{$\begin{array}{l}\text { Ceylan } \\
\text { et al. (2020) }\end{array}$} & Bipolar disorder & 69 & \multirow{2}{*}{$\begin{array}{l}\text { Peripheral blood } \\
\text { plasma }\end{array}$} & \multirow[t]{2}{*}{ Exosomes } & \multirow{2}{*}{$\begin{array}{l}\text { Genome-wide } \\
\text { using RT-qPCR } \\
\text { miRCURY LNA } \\
\text { miRNA miRNome } \\
\text { PCR Panels }\end{array}$} & \multirow{2}{*}{$\begin{array}{l}\text { miR-484, miR-652-3p, } \\
\text { miR-142-3p; all } \downarrow ; \\
\text { miR-185-5p } \uparrow\end{array}$} & \multirow{2}{*}{$\begin{array}{l}\text { PI3K/Akt signaling, fatty } \\
\text { acid } \\
\text { biosynthesis/metabolism, } \\
\text { extracellular matrix and } \\
\text { adhesion pathways }\end{array}$} \\
\hline & $\begin{array}{l}\text { Nonpsychiatric } \\
\text { control }\end{array}$ & 41 & & & & & \\
\hline \multirow{2}{*}{$\begin{array}{l}\text { Zhang et al. } \\
\text { (2017) }\end{array}$} & Depression & 1 & \multirow{2}{*}{$\begin{array}{l}\text { Peripheral blood } \\
\text { serum }\end{array}$} & \multirow[t]{2}{*}{ Exosomes } & \multirow{2}{*}{$\begin{array}{l}\text { Genome-wide } \\
\text { analysis: small } \\
\text { RNA-seq }\end{array}$} & \multirow[b]{2}{*}{$\begin{array}{l}\text { miR-1255a, miR-3161, } \\
\text { miR-99a-3p, miR-205-5p, } \\
\text { miR-26a-1-3p, } \\
\text { miR-139-5p, } \\
\text { miR-7849-3p, } \\
\text { miR-195-5p, } \\
\text { hsamiR-125b-2-3p, } \\
\text { miR-664a-3p, let-7c-5p, } \\
\text { and miR-197-3p, all } \uparrow ; \\
\text { miR-499a-5p, } \\
\text { miR-4732-3p, } \\
\text { miR-222-5p, miR-1291, } \\
\text { miR-668-3p, miR-425-3p, } \\
\text { miR-6511a-3p, } \\
\text { miR-145-3p, } \\
\text { miR-200a-3p, } \\
\text { miR-143-3p, } \\
\text { miR-196b-5p, } \\
\text { miR-99a-5p, miR-144-3p, } \\
\text { miR-584-5p, miR-210-3p, } \\
\text { miR-183-5p, miR-107, } \\
\text { miR-130b-5p, } \\
\text { miR-589-5p, } \\
\text { miR-1910-5p, all } \downarrow\end{array}$} & \multirow[b]{2}{*}{$\begin{array}{l}\text { Upregulated genes: } \\
\text { chromatin/histone } \\
\text { modification, } \\
\text { post-transcriptional } \\
\text { regulation of gene } \\
\text { expression, neurotrophin } \\
\text { signaling pathway, } \\
\text { immune system function, } \\
\text { inflammation, depression; } \\
\text { downregulated genes: } \\
\text { apoptotic signaling, } \\
\text { oxidation, hypoxia, cell } \\
\text { cycle, cellular growth, } \\
\text { depression }\end{array}$} \\
\hline & $\begin{array}{l}\text { Nonpsychiatric } \\
\text { control }\end{array}$ & 1 & & & & & \\
\hline
\end{tabular}

BA: Brodmann area; LNA: Locked nucleic acids; RNA-seq: RNA sequencing; RT-qPCR: Quantitative real-time PCR.

system enzymes, SAT1 and SMOX, have been previously associated with suicidal behavior. The prefrontal cortex (Brodmann area 44) of suicide victims with a history of depression and of healthy control subjects was compared for the analysis of expression of ten miRNAs (miR-124a, miR-139-5p, miR-195, miR-198, miR-320c, miR-33b, miR-34a, miR-34c-5p, miR-497, miR-873) that in silico were predicted to target the 3'UTR of both $S A T 1$ and $S M O X$. Gene expression of $S A T 1$ and $S M O X$ was downregulated, whereas four miRNAs (miR-34c-5p, miR139-5p, miR-195, miR-320c) were upregulated in suicide victims compared with the control group. Significant negative correlations between expression levels were observed for SAT1 and miR-34c-5p, and SMOX and miR139-5p, whereas miR-320c was negatively correlated with both $S A T 1$ and $S M O X$. Interestingly, miR-320c showed 
low evolutionary conservation, which might indicate its association with cognitive function [28]. The same four miRNAs were validated in a different region of the prefrontal cortex (Brodmann area 9) on a new set of subjects. Similarly, expression of SAT1 and its isoforms was downregulated in both depressed subjects who died from suicide and depressed subjects who died by other causes compared with healthy control subjects, which indicated the possible association of $S A T 1$ with depression over suicidal behavior. Despite being previously upregulated in a study by Lopez et al. (2014), the four miRNAs studied showed no significance when comparing the groups, nor did they correlate with $S A T 1$ expression [35].

Suicidal behavior is often accompanied by additional comorbidities, which can make it harder to distinguish between changes associated with suicidal behavior and other psychopathologies. For example, a whole transcriptome study compared mRNA and miRNA expression in the prefrontal cortex of depressed subjects who died from suicide, depressed subjects who died by other causes and healthy control subjects, which made it possible to attribute findings to either depression or suicidal behavior. While there were multiple genes with differential expression between all of these studied groups, no statistically significant differences in miRNA expression were found [34]. Another complex study that included multiple groups of subjects investigated the role of the main proinflammatory cytokine, TNF- $\alpha$, and its involvement in suicidal behavior. A study by Wang et al. (2018) compared three study cohorts: suicide victims with either depression or other psychiatric disorders and control subjects without psychiatric disorders; depressed subjects who died from either suicide or by other means and healthy control subjects; and depressed patients with suicidal ideation and healthy control subjects. Analysis of candidate miRNAs that potentially target $T N F-\alpha$ identified upregulation of miR-19a-3p in the dorsolateral prefrontal cortex of suicide victims regardless of their psychopathologies and only in a depressed subject who died by suicide. Similarly, expression of miR-19a-3p was increased in the blood of depressed patients with suicidal ideation. Changes in miR-19a-3p therefore appear to be specific for suicidal behavior only. Although $T N F-\alpha$ expression was upregulated in all groups of depressed and suicide subjects compared with the control groups, miR-19a-3p did not appear to target TNF- $\alpha$ transcripts, which indicated the involvement of other complex regulatory mechanisms [31].

Multiple brain regions are involved in emotional processing and cognition, which includes the locus coeruleus, a brainstem nucleus that is responsible for most of the brain norepinephrine (also known as noradrenaline) synthesis. A comparison between the locus coeruleus of major depressive disorder (MDD) suicide victims and healthy control subjects identified 13 miRNAs with altered expression. Of these, ten were upregulated in the suicide victims (miR-17-5p, miR-20b-5p, miR-106a-5p, miR-330-3p, miR-541-3p, miR-582-5p, miR-890, miR-99b-3p, miR550-5p, miR-1179), and the expression was downregulated in three (miR-409-5p, let-7g-3p, miR-1197). Additional in silico analysis revealed high complexity of miRNAs and potential miRNA target gene regulatory networks that contained pathways commonly implicated in depression and suicidal behavior. The results of a computer-generated regulatory network were verified by examining gene expression of the depression-related genes RELN, GSK-3 $\beta$ and $M A O A$, which were downregulated in suicide victims [37].

The serotonin system is a complex neurotransmitter system that is associated with numerous mental states. A recent study reported decreased palmitoylation of inhibitory serotonin receptor 5-HT1A in the prefrontal cortex of suicide victims compared with a control group. This reduction was mediated by miRNAs. Palmitoylation is a process in which fatty acids are covalently bound to predominately cysteine amino acids. ZDHHC21 is an enzyme that is involved in palmitoylation of proteins, which includes 5-HT1A. Using RT-qPCR, decreased levels of $Z D H H C 21$ gene expression and increased levels of miR-30e were identified in the prefrontal cortex of suicide victims, with one of the target binding sites of miR-30e as $Z D H H C 21$. Similarly, mice models with knockdown of $Z D H H C 21$ showed depression-like symptoms. Increased miR-30e levels therefore appear to affect the expression of $Z D H H C 21$, which in turn attenuates palmitoylation of 5-HT1A [30].

It has been known that psychiatric treatments (e.g., antidepressants) can have lower treatment responses and can in some cases worsen suicidal ideation. Two 8-week randomized trials compared clinical and molecular indicators in MDD patients treated with either duloxetine (selective serotonin and norepinephrine reuptake inhibitor and antidepressant) or placebo. In the first trial, downregulation of four miRNAs (miR-146a-5p, miR-146b-5p, miR24-3p, miR-425-3p) was associated with response to treatment. These data were validated in the prefrontal cortex of suicide victims with depression. Interestingly, all four of these miRNAs were upregulated in brain tissue of suicide victims with depression compared with control subjects. These altered miRNAs have been associated with MAPK and Wnt pathways, both of which can be modulated by stress and have already been linked to depression [32]. In the second trial, suicidal ideation was observed more frequently in the placebo group (16.8\% of patients) versus the duloxetine group (9.8\% of patients). Expression of two miRNAs (miR-3688, miR-5695) was upregulated in 
the blood of MDD patients treated with duloxetine and was predictive of treatment-worsening suicidal ideation. The target genes of miR-3688 and miR-5695 are not yet known, but in silico gene ontology analysis has indicated "regulation of neurogenesis" as the most significantly enriched term. These data are interesting because the authors studied whole blood. miRNAs can travel through the bloodstream packed inside exosomes, and thus these data might reflect the ongoing processes in the central nervous system [27].

\section{miRNAs in extracellular vesicles, \& schizophrenia, bipolar disorder \& depression}

The most comprehensive study on exosomes in psychiatric disorders was performed by Du et al. [40], who investigated miRNA profiles genome wide. They performed a two-step analysis that included training and testing cohorts of SZ patients and control subjects. With their newly identified panel of 11 miRNAs, the SZ patients and control subjects could be classified with almost $90 \%$ accuracy in the training cohort, and with approximately $75 \%$ accuracy in the testing cohort. The testing cohort included first episode, drug-free SZ patients, and it returned 18 miRNAs, 12 of which were upregulated and six downregulated, with significant expression changes compared with control subjects in a genome-wide analysis. miR-206, miR-145-5p and miR-133a-3p showed twofold increases in the SZ patients. The results were validated on a new set of SZ patients and control subjects, with interrogation of 265 miRNAs selected from an initial high-throughput analysis. Among the 29 miRNAs that showed significant expression changes, seven had more than twofold changes in the SZ patients compared with the control subjects. Also, miR-206, miR-145-5p and miR-133a-3p were again defined, which confirmed the data from the first training cohort. The pathway enrichment analysis showed significant enrichment in pathways for O-glycosylation, extracellular matrix-receptor interactions, the mTOR signaling pathway, neurotransmitter receptors, dendritic spine development and BDNF. These data were validated on a testing cohort of $100 \mathrm{SZ}$ patients (first-episode, drug-free patients and chronically treated patients) and 100 control subjects. miR-206 was increased in the firstepisode, drug-free SZ patients compared with the control subjects, and miR-144-3p levels were decreased in the SZ patients; however, after long-term medication, these were restored to normal levels. miR-619-5p was also increased in $\mathrm{SZ}$ patients, independent of medication. Validation of these data was extended further, and targets of miRNAs were tested (BDNF, O-glycosylation associated genes GALNT8, GLANT15 and GLANT18), which confirmed the bioinformatics analysis [40].

The initial study on exosomes in psychiatric disorders was performed by Banigan et al. (2013), who were the first to analyze miRNAs in frozen post-mortem brain samples [41]. The screening of 312 miRNAs was analyzed with multiclass testing to identify a set of miRNAs that could be used for differential analysis of SZ and BD patients and control subjects. Using prediction analysis of microarrays, they defined 21 miRNAs with derived q-values of $0 \%$. These 21 miRNAs were used to cluster the samples; the SZ samples segregated from the BD and control samples, whereas the BD samples could not be distinguished from the control subjects. However, the analysis of the $\mathrm{BD}$ and control samples only identified seven miRNAs that differentiated between these two groups. The data from their Luminex assay were further validated using RT-qPCR; however, the groups of samples used for each of these types of gene expression analysis were not stratified and were partially overlapping. In the RT-qPCR experiments, six miRNAs were analyzed: miR-31, miR-15b, miR-29c and miR-497 were among the highest ranked according to the likelihood to be differentially expressed in both SZ and BD, with miR-219 and miR-149 only in BD. Two of the selected miRNAs were shown to be differentially expressed, miR-29c in the BD samples (2.77-fold increase) and miR-497 in the SZ samples (2.35-fold increase) compared with the control subjects. miR-29c has previously been linked to cell-adhesion components, and miR-497 to neurodegenerative diseases and heart disease [41]. Another study on a similar sample set was performed by the same group, only this time the previously identified miRNAs associated with neuropathology (miR-29c, miR-31, miR-15b, miR-497, miR-219, miR-149) were tested for Brodmann area 24, which is known to have reduced glial cell numbers in BD patients. Extracellular vesicle miRNAs were isolated from fresh-frozen tissue, and miR-149, which is associated with inhibition of proliferation of glial cells, was increased in the BD samples (4.45-fold increase). These data were further supported with an expression analysis in the micro-dissected glial and neuronal cells, where there were significant increases in glial cells in BD patients. This implied that the glial cells might be the ones that significantly contribute to increased miR-149 in extracellular vesicles [42].

Fries et al. (2019) performed a genome-wide miRNA analysis on extracellular vesicles from blood plasma [44]. Their findings suggested some nominal differences in miRNA expression between BD patients and the control subjects. The enrichment analysis of these miRNAs indicated signaling pathways and gene ontology terms that could be associated with axon guidance mediated by netrin and with the pathways for endothelin signaling, 5-HT2 
receptor-mediated signaling, $\beta 1 / \beta 2$-adrenergic receptor signaling and androgen receptor signaling. The miRNAs identified were further linked to expression in specific brain areas (miR-4516, miR-6068, miR-8060, miR-1268b, miR-29c-3p, miR-5739, miR-6090, miR-3135b, miR-7975), which might support the concept that some of the extracellular vesicles in the periphery do actually come from the brain. Among the differentially expressed miRNAs, six were designated to the netrin pathway, with targeting of netrin 1 (miR-133a-3p, miR-21-5p), netrin 3 (miR-133a-3p, miR-142-3p, miR-22-3p, 92a-3p), netrin 4 (miR-22-3p, miR-92a-3p), netrin G1 (miR-133a3p, miR-142-3p, miR-21-5p, miR-22-3p, miR-92a-3p) and netrin G2 (miR-133a-3p, miR-142-3p, miR-22-3p, miR-92a-3p) [44].

For Ceylan et al. (2020) [43], miRNAs from exosomes of BD patients compared with control subjects revealed higher expression levels for five miRNAs (miR-185-5p, miR-25-3p, miR-92a-3p, miR-376b-3p, let-7i-5p) and significantly lower expression levels for eight miRNAs (miR-484, miR-652-3p, miR-142-3p, miR-30b-5p, miR126-3p, miR-15a-5p, miR-126-5p, miR-301a-3p). However, after correction for multiple testing, only miR-1855p, miR-484, miR-652-3p and miR-142-3p remained significant. The pathway analysis here showed significant association with the PI3K-Akt signaling and fatty acid biosynthesis pathways. Analysis of different BD states (i.e., euthymia, mania, depression) showed no associations with the miRNA expression profiles, although using receiver-operating characteristic analyses, the combination of miR-185-5p, miR-484, miR-652-3p and miR-142-3p showed high sensitivity and moderate specificity for diagnosis of BD patients [43].

A single study was performed on depression and miRNA profiling of exosomes, by Zhang et al. (2017). In this study, only one patient and one control were enrolled, but the gene ontology analysis of the miRNA sequencing results indicated genes that had already been established in the molecular genetics of depression, such as genes involved in histone/chromatin modifications, the neurotrophin signaling pathway and immune responses [39].

\section{Discussion}

To keep clinicians and other professionals up to date, we carried out an extensive literature search here on suicidal behavior and miRNAs, which are one of the most stable and tissue-specific epigenetic biomarkers that can be easily identified with affordable tests.

The first aim of this review was to determine the miRNAs that can maybe be used as biomarkers in suicidal behavior research, and as biomarkers that might in future serve as complementary tools to current clinical interviews, to provide more replicable and precise diagnoses. Altogether, 13 studies were included in this systematic review. Overall, 56 unique miRNAs were identified that differed significantly in their expression between suicide victims and control subjects. These miRNAs identified are included in various pathways, including some previously associated with suicidal behavior, including neurogenesis [45], inflammation and stress responses [46]; Wnt signaling [47]; and the polyamine system [48]. However, no single clear direction arises from these pathways identified, which indicates the complexity and divergence of the miRNA networks. Looking at miRNAs individually, only one miRNA (miR330-3p) was identified by two independent studies (both of which used similar methodological approaches, with TLDA-based miRNA profiler). miR-330-3p is believed to target multiple genes associated with neuropsychiatric states (e.g., GRIA3, CREM and GRM5) [37]. Expression of miR-330-3p might be tissue specific, as one study reported its upregulation in the locus coeruleus [37], and the other reported its downregulation in the prefrontal cortex [38]. Interestingly, gene expression of glutamate receptors has been studied before in both the locus coeruleus and prefrontal cortex in depressed patients, the majority of whom died from suicide. Increased expression of receptors was observed only in the locus coeruleus of the depressed patients, which indicated a disruption of the locus coeruleus in this psychopathology [49].

The secondary aim of this review was to investigate the contemporary findings on miRNAs in exosomes or extracellular vesicles in psychiatry, based on their ability to cross the blood-brain barrier and thus potentially carry information from the CNS to the periphery [50]. Six studies were identified that included subjects with BD, SZ and depression, and collectively 76 unique miRNAs were specifically defined for either exosomes or somewhat larger extracellular vesicles. The differentially expressed miRNAs are involved in neurodegenerative diseases [51] and neuroinflammation [52] and also in various pathways associated with psychiatric disorders, such as nerve growth factors pathways [53], Wnt signaling [54] and others. The miRNAs identified that overlapped between at least two studies were miR-144-3p (observed twice) and miR-29c (observed three times). PubMed searches on miR-144-3p returned records that were mainly associated with cancer, and therefore we checked the in silico prediction of the miRNA functions. Here, 238 target proteins were listed in RNAcentral [55], whereas among the gene ontology terms, the most interesting hits were inflammatory responses, IL-1 $\beta$ and IL-6, and TNF secretion. 
Thus, inflammation is believed to have an important role in the pathophysiology of neuropsychiatric disorders and their clinical progression, whereas proinflammatory cytokines might modulate mood behavior, cognition and brain plasticity [56]. According to RNAcentral, through its mi-29-3p and mi-29-5p miRNAs, the precursor miRNA miR-29 has been associated with cell proliferation and apoptotic processes, and linked to exosomes. It is known that it is induced by canonical Wnt signaling [57] that is antagonized by GSK3, which is a target of lithium inhibition and also a regulator of neurogenesis and neurosignaling [54].

The third aim of this review was to search for any overlap between miRNAs located in peripheral tissues and the CNS, with the hope of identifying more easily accessible blood biomarkers that reflect the miRNA expression state of the brain. Comparing miRNAs identified through direct studies and studies that examined exosome encapsulated miRNAs, four miRNAs overlapped. miR-139-5p was upregulated in two studies, in the prefrontal cortex of depressed suicide victims [28] and in the peripheral blood serum of a single depressed patient [39], which indicated its involvement in both the polyamine system (e.g., SMOX) and chromatin remodeling (i.e., histone acetylation). Furthermore, the same two groups of researchers showed that miR-425-3p was downregulated in exosomes [39] and upregulated in the prefrontal cortex of depressed suicide victims [32]. Expression of miR-142-3p was dysregulated in three studies, with downregulation in the prefrontal cortex of antidepressant-free suicide victims with depression [36] and in the peripheral blood serum of patients with BD [43], and in another study, upregulation in peripheral blood serum of patients with BD [44]. miR-142-3p appears to be an important regulator of genes of the netrin pathway (with genes of various netrin proteins targeted, which are involved in axon guidance and therefore serve as important players in brain plasticity) and the PI3K-Akt pathway (pathway activation associated with pharmacological treatments; e.g., lithium). miR-497 was downregulated in the prefrontal cortex (Brodmann area 9) of antidepressant-free suicide victims with depression [36], whereas it was upregulated in exosomes isolated from the prefrontal cortex (Brodmann area 9) of SZ patients [41]. miR-497 is believed to be involved in neurodegenerative diseases and might promote ischemic neuronal death.

While reviewing the studies included in this systematic review, some general limitations were observed. All but one study [34] reported at least one statistically significant miRNA that was differentially expressed in suicide victims, which opens the question of negative results bias. It is not possible to estimate the amount of unpublished negative results where there were no significant changes in miRNA expression, making the concept of miRNAs as biomarkers particularly unclear. Furthermore, because all of the studies mentioned here examined miRNA in subjects with mental disorders, it could be that the miRNAs identified are associated more with different mental disorders than with suicidal behavior specifically.

The studies reviewed used different approaches for their study designs and molecular analyses, and these differences in the methodologies used make it harder to compare the data. The first caveat would be the differences in tissue selection and quality, especially if post-mortem tissue was used. Another potential source of bias is the miRNA isolation, as there are several commercially available kits [58]. Similarly, isolation of exosomes can vary because there is no clear consensus about what size selection defines exosomes in particular compared with other types of extracellular vesicles. Likewise, exosomes are believed to carry cargoes that are specifically based on the type of cell they originated from. Also, although the Minimal Information for Studies of Extracellular Vesicles guidelines are in place, not all studies follow them yet [59].

Further technical issues relate to the miRNA analytical approach. Roughly half of the studies analyzed here used the candidate miRNA approach and RT-qPCR, which means that only the selected miRNAs are analyzed, thus limiting of the potential information gained. RT-qPCR is a well-known methodology that is used to determine mRNA expression, so it is no surprise that the same methodology has been adapted to miRNA detection. These data are usually normalized to a reference gene, and although there are commonly used reference genes, there is again a lack of standardization. The other half of the studies analyzed here used wider approaches, with analysis of miRNAs using miRNA profiler approaches (RT-qPCR based, such as "locked nucleic acids" and TLDA or hybridization-based platforms) or small RNA-seq methods. Sequencing and microarrays are less sensitive than RTqPCR, but they offer a broader overview of potential miRNAs. Additionally, sequencing enables identification of novel miRNAs, whereas miRNA profilers can detect only the preselected miRNAs [60]. Whatever the methods used, standardization of the preanalytical and analytical phases of these procedures is necessary to enable identification of biomarkers suitable for translation into clinical practice.

In neuropsychiatry, miRNAs represent just the research phase, and much more effort has to be invested in the identification of miRNAs. These need to be focused on how miRNAs can be translated into clinical practice, in terms of disease detection and identification, prediction of predisposition of a patient for a disease, prognosis of 
clinical courses, progression and regression of diseases and identification of specific subgroups within diagnostic syndromes [61]. Biomarkers, as also applied to miRNAs, should be objective indicators of health and disease, and they need to fulfill several criteria. In the clinical setting, high sensitivity and specificity of biomarkers is needed to prevent false positives and false negatives during diagnosis [62], and miRNAs are still on their way to reaching the required levels in this context [63]. Their analysis should be based on uncomplicated molecular biology methods that are easily reproduced and that are validated, sensitive and specific [61]. The easy and cost-effective low-throughput qRT-PCR approach is the golden standard for mRNA analysis, and therefore this approach is often used also in miRNA studies. However, it has already been suggested that a panel of several miRNAs (i.e., an miRNA signature) or RNA sequencing (using next-generation sequencing) are more effective than single miRNA analysis [62] because these can allow more specific diagnosis of the disease. At the same time, however, independent reproduction and validation of miRNA signatures/next-generation sequencing are less frequently performed [64]. Furthermore, when considering the clinical laboratory setting, miRNAs have several advantages, as they are stable and resistant to endogenus RNAse degradation and can endure long-term storage and multiple freeze-thaw cycles in different body fluids [63], which enables easy sample handling and storing. However, currently there are many approaches for isolation and processing of miRNAs, and therefore the establishment of standard operating procedures would enable more standardized approaches across different studies. Currently, the discrepancies among the data from different studies might be highly dependent on the versatility of the methodological approaches used.

Although several issues regarding the use of miRNAs in the clinical setting have been indicated here, an important advantage of miRNAs should also be noted - namely, their presence in bodily fluids where they can be reached through minimally or even noninvasive procedures using liquid biopsies, and also their ability to cross the bloodbrain barrier and therefore to reflect the situation in the CNS in terms of the (patho)physiological status of particular brain diseases.

\section{Conclusion}

In this systematic review, we have shown that the noncoding genome has important potential that can be further exploited. Today, we know that approximately $1 \%$ of the human genome codes for proteins; furthermore, sequencing of the entire exome has not provided answers related to many complex, multifactorial illnesses [65], among which psychiatric disorders are included. This implies that we have to go beyond the annotated functions of the genome. A comprehensive consortium on the noncoding genome, the ENCODE [66], was established in 2003. Other databases, such as miRBase [67], RNAcentral [55] and NONCODE [68], are collecting data particularly on ncRNAs, which will enable in silico target prediction and screening for ncRNA-target interactions and gene ontology annotations to support in vivo measurements. The knowledge that miRNAs effectively regulate gene expression and that most of the miRNAs are expressed in the brain makes this even more intriguing because miRNAs can also be transported through the blood-brain barrier in extracellular vesicles to reach distant locations in the body. The availability of miRNAs in the periphery gives them particular value in biomolecular psychiatry research. However, with this systematic review, we wanted to focus attention on better planning of studies to avoid the bias that can stem from poor study design that will not provide the background to be able to establish better patient treatment and prognosis.

\section{Future perspective}

The definition of biomarkers in psychiatry remains elusive, but contemporary molecular biology tools are now opening opportunities for further research. Studies of peripheral tissues (e.g., blood) and their association with the status of central nervous tissues (e.g., the brain) remain of great interest, although at the same time, they can come with extreme risk, especially when target tissues are not available for data confirmation. However, success in such high-risk-high-gain approaches should be particularly beneficial for the treatment and/or monitoring of frequently concomitant psychiatric comorbidities, as noninvasive molecular genetics tests would support the current interview-based psychiatrist decisions regarding patient diagnosis and treatment. Liquid biopsies appear to be an elegant solution, and in the blood, the nucleic acids can be found in numerous cell types, in extracellular vesicles and also as cell-free circulating DNA and RNA. Extracellular vesicles are excreted by different cells throughout the body and come in different sizes and from different intracellular origins. They carry RNA (mRNA, miRNA), DNA, protein and lipids [69]. Therefore, like exosomes, extracellular vesicles might be a promising option because they may reflect the status of the CNS. 
In studies of suicidal patients in clinical cohorts, changes in the most studied epigenetic marker - DNA methylation of genes - have often been associated with suicide or depression (e.g., BDNF, NR3C1, FKBP5, CRHBP, CRHC1), and differences in gene methylation and expression have been linked to functional MRI of particular brain regions, as well as strong suicidal ideation and suicide attempts [70]. On the basis of this evidence, it appears that the search for peripheral biomarkers in suicidal behavior should provide applicable results that will be promising for translation into clinical practice.

\section{Executive Summary}

- Suicide remains an important public health problem, despite better awareness and development of different preventive strategies. Early detection of suicidal behavior is of paramount importance for preventive measures.

- Suicidal behavior can be influenced by numerous factors, including the mechanisms of epigenetic regulation.

- miRNAs are a class of short single-stranded noncoding RNAs. By binding to the 3'UTRs of genes, they can prevent transcription and are therefore involved in regulation of numerous cellular pathways.

- miRNAs can also be found inside exosomes, the extracellular vesicles secreted by almost all cells.

- To date, 13 studies have evaluated the expression levels of miRNAs, with 56 unique miRNAs identified as differentially expressed in suicide victims.

- Exosomal miRNAs have not been studied extensively to date, with six studies that have identified 76 unique miRNAs as differentially expressed in patients with psychiatric disorders.

- Differentially expressed miRNAs are involved in various pathways, including those previously associated with neurodegenerative diseases and suicidal behavior, including neurogenesis, Wnt signaling, inflammation and stress responses.

- For three miRNAs, overlap between CNS tissue and blood-derived exosomes has been reported (miR-139-5p, miR-425-3p, miR-142-3p).

- miRNAs appear to represent promising potential biomarkers of suicidal behavior. Identification of miRNAs that are differentially expressed in both the CNS and peripheral tissues should provide valuable information that can reflect the state of the brain through a simple blood test.

\section{Acknowledgments}

The authors thank Dr Christopher Berrie for scientific English editing of the manuscript.

Financial and competing interest disclosure

The authors thank the Slovenian Research Agency for funding the research program grant no. P1-0390 and research project grant no. J3-7132 and Grant No. Z3-2653. The funders had no role in the preparation or publication of the manuscript. The authors have no other relevant affiliations or financial involvement with any organization or entity with a financial interest in or financial conflict with the subject matter or materials discussed in the manuscript apart from those disclosed.

No writing assistance was utilized in the production of this manuscript.

Open access

This work is licensed under the Attribution-NonCommercial-NoDerivatives 4.0 Unported License. To view a copy of this license, visit http://creativecommons.org/licenses/by-nc-nd/4.0/

\section{References}

Papers of special note have been highlighted as: $\bullet$ of interest; $\bullet \bullet$ of considerable interest

1. World Health Organization. Global Health Estimates (2018). www.who.int/healthinfo/global_burden_disease/en/

2. Marusic A, Farmer A. Genetic risk factors as possible causes of the variation in European suicide rates. Br. J. Psychiatry 179, 194-196 (2001).

3. Bertolote JM, Fleischmann A. Suicidal behavior prevention: WHO perspectives on research. Am. J. Med. Genet. C, Semin. Med. Genet. 133C(1), 8-12 (2005).

4. Brent DA, Mann JJ. Family genetic studies, suicide, and suicidal behavior. Am. J. Med. Genet. C Semin. Med. Genet. 133C(1), 13-24 (2005).

5. Bondy B, Buettner A, Zill P. Genetics of suicide. Molec. Psychiatry 11(4), 336-351 (2006).

6. Brezo J, Paris J, Turecki G. Personality traits as correlates of suicidal ideation, suicide attempts, and suicide completions: a systematic review. Acta Psychiat. Scand. 113(3), 180-206 (2006). 
7. Agerbo E, Nordentoft M, Mortensen PB. Familial, psychiatric, and socioeconomic risk factors for suicide in young people: nested case-control study. Brit. Med. J. 325(7355), 74 (2002).

8. Qin P, Agerbo E, Mortensen PB. Suicide risk in relation to family history of completed suicide and psychiatric disorders: a nested case-control study based on longitudinal registers. Lancet 360(9340), 1126-1130 (2002).

9. Qin P, Agerbo E, Mortensen PB. Suicide risk in relation to socioeconomic, demographic, psychiatric, and familial factors: a national register-based study of all suicides in Denmark, 1981-1997. Am. J. Psychiatry 160(4), 765-772 (2003).

10. Runeson B, Asberg M. Family history of suicide among suicide victims. Am. J. Psychiatry 160(8), 1525-1526 (2003).

11. Tidemalm D, Runeson B, Waern M et al. Familial clustering of suicide risk: a total population study of 11.4 million individuals. Psycholog. Med. 41(12), 2527-2534 (2011).

12. Voracek M, Loibl LM. Genetics of suicide: a systematic review of twin studies. Wiener klinische Wochenschrift 119(15-16), 463-475 (2007).

13. Von Borczyskowski A, Lindblad F, Vinnerljung B et al. Familial factors and suicide: an adoption study in a Swedish national cohort. Psycholog. Med. 41(4), 749-758 (2011).

14. Asberg M, Traskman L, Thoren P. 5-HIAA in the cerebrospinal fluid. A biochemical suicide predictor? Arch. Gen. Psychiatry 33(10), 1193-1197 (1976).

15. Zai CC, De Luca V, Strauss J et al. Genetic factors and suicidal behavior. In: The Neurobiological Basis of Suicide. Dwivedi Y (Ed.). CRC Press, FL, USA (2012).

16. Andriessen K, Videtic-Paska A. Genetic vulnerability as a distal risk factor for suicidal behaviour: historical perspective and current knowledge. Zdravstveno varstvo 54(3), 238-251 (2015).

17. Van Vliet J, Oates NA, Whitelaw E. Epigenetic mechanisms in the context of complex diseases. Cell. Molec. Life Sci. 64(12), 1531-1538 (2007).

18. Relton CL, Davey Smith G. Two-step epigenetic Mendelian randomization: a strategy for establishing the causal role of epigenetic processes in pathways to disease. Int. J. Epidemiol. 41(1), 161-176 (2012).

- Epigenetic mechanisms and disease.

19. Diamantopoulos MA, Tsiakanikas P, Scorilas A. Non-coding RNAs: the riddle of the transcriptome and their perspectives in cancer. Ann. Transl. Med. 6(12), 241 (2018).

20. Kozomara A, Birgaoanu M, Griffiths-Jones S. MIRbase: from microRNA sequences to function. Nucleic Acids Res. 47(D1), D155-D162 (2019).

21. Saeedi S, Israel S, Nagy C, Turecki G. The emerging role of exosomes in mental disorders. Transl. Psychiatry 9(1), 122 (2019).

-. Extensive paper on the biogenesis, role and potential of exosomes in mental disorders.

22. Gruzdev SK, Yakovlev AA, Druzhkova TA et al. The missing link: how exosomes and miRNAs can help in bridging psychiatry and molecular biology in the context of depression, bipolar disorder and schizophrenia. Cell. Molec. Neurobiol. 39(6), 729-750 (2019).

- Synopsis of miRNA studies in depression, bipolar disorder and schizophrenia.

23. Serafini G, Pompili M, Innamorati M et al. The role of microRNAs in synaptic plasticity, major affective disorders and suicidal behavior. Neurosci. Res. 73(3), 179-190 (2012).

24. Moher D, Liberati A, Tetzlaff J et al Preferred reporting items for systematic reviews and meta-analyses: the PRISMA statement. PLoS Med. 6(7), e1000097 (2009).

25. Hong QN, Fàbregues S, Bartlett G et al. The mixed methods appraisal tool (MMAT) version 2018 for information professionals and researchers. Educat. Informat. 34, 1-7 (2018).

26. Aschrafi A, Verheijen JM, Gordebeke PM et al. MicroRNA-326 acts as a molecular switch in the regulation of midbrain urocortin 1 expression. J. Psychiatry Neurosci. 41(5), 342-353 (2016).

27. Belzeaux R, Fiori LM, Lopez JP et al. Predicting worsening suicidal ideation with clinical features and peripheral expression of messenger RNA and microRNA during antidepressant treatment. J. Clin. Psychiatry 80(3), 18m12556 (2019).

28. Lopez JP, Fiori LM, Gross JA et al. Regulatory role of mirnas in polyamine gene expression in the prefrontal cortex of depressed suicide completers. Int. J. Neuropsychopharmacol. 17(1), 23-32 (2014).

29. Maussion G, Yang J, Yerko V et al. Regulation of a truncated form of tropomyosin-related kinase b (TRKb) by hsa-miR-185* in frontal cortex of suicide completers. PLoS ONE. 7(6), e39301 (2012).

30. Gorinski N, Bijata M, Prasad S et al. Attenuated palmitoylation of serotonin receptor 5-HT1a affects receptor function and contributes to depression-like behaviors. Nat. Commun. 10(1), 3924 (2019).

31. Wang Q, Roy B, Turecki G et al. Role of complex epigenetic switching in tumor necrosis factor- $\alpha$ up-regulation in the prefrontal cortex of suicide subjects. Am. J. Psychiatry 175(3), 262-274 (2018).

32. Lopez JP, Fiori LM, Cruceanu C et al. MicroRNAs 146a/b-5 and 425-3p and 24-3p are markers of antidepressant response and regulate MAPK/Wnt-system genes. Nat. Commun. 8, 15497 (2017). 
33. Torres-Berrio A, Lopez JP, Bagot RC et al. DCC confers susceptibility to depression-like behaviors in humans and mice and is regulated by miR-218. Biol. Psychiatry 81(4), 306-315 (2017).

34. Pantazatos SP, Huang YY, Rosoklija GB et al. Whole-transcriptome brain expression and exon-usage profiling in major depression and suicide: evidence for altered glial, endothelial and ATPase activity. Molec. Psychiatry 22(5), 760-773 (2017).

35. Pantazatos SP, Andrews SJ, Dunning-Broadbent J et al. Isoform-level brain expression profiling of the spermidine/spermine N1-acetyltransferase1 (Sat1) gene in major depression and suicide. Neurobiol. Dis. 79, 123-134 (2015).

36. Smalheiser NR, Lugli G, Rizavi HS et al. MicroRNA expression is down-regulated and reorganized in prefrontal cortex of depressed suicide subjects. PLoS ONE 7(3), e33201 (2012).

- $\quad$ First study on suicidal behavior and miRNA.

37. Roy B, Wang Q, Palkovits M et al. Altered miRNA expression network in locus coeruleus of depressed suicide subjects. Sci. Rep. 7(1), 4387 (2017).

38. Smalheiser NR, Lugli G, Zhang H et al. Expression of microRNAs and other small RNAs in prefrontal cortex in schizophrenia, bipolar disorder and depressed subjects. PLoS ONE 9(1), e86469 (2014).

39. Zhang Y, Zhao Y, Tian C et al. Differential exosomal microRNA profile in the serum of a patient with depression. Eur. J. Psychiatry 32(3), 105-112 (2017).

40. Du Y, Yu Y, Hu Y et al. Genome-wide, integrative analysis implicates exosome-derived microRNA dysregulation in schizophrenia. Schizophr. Bull. 45(6), 1257-1266 (2019).

- Genome-wide study of schizophrenia miRNA in exosomes from blood serum.

41. Banigan MG, Kao PF, Kozubek JA et al. Differential expression of exosomal microRNAs in prefrontal cortices of schizophrenia and bipolar disorder patients. PLoS ONE 8(1), e48814 (2013).

- $\quad$ First study on exosomes in mental disorders.

42. Choi JL, Kao PF, Itriago E et al. MiR-149 and miR-29c as candidates for bipolar disorder biomarkers. Am. J. Med. Genet. B Neuropsychiatr. Genet. 174(3), 315-323 (2017).

43. Ceylan D, Tufekci KU, Keskinoglu P et al. Circulating exosomal microRNAs in bipolar disorder. J. Affect. Disord. 262, 99-107 (2020).

44. Fries GR, Lima CNC, Valvassori SS et al. Preliminary investigation of peripheral extracellular vesicles' microRNAs in bipolar disorder. J. Affect. Disord. 255, 10-14 (2019).

45. Dwivedi Y. Brain-derived neurotrophic factor in suicide pathophysiology. In: The Neurobiological Basis of Suicide Dwivedi Y (Ed.). CRC Press/Taylor \& Francis, Boca Raton (FL) (2012).

46. Brundin L, Erhardt S, Bryleva EY et al. The role of inflammation in suicidal behaviour. Acta Psychiatr. Scand. 132(3), 192-203 (2015).

47. Flory JD, Donohue D, Muhie $S$ et al. Gene expression associated with suicide attempts in US veterans. Translat. Psychiatry 7(9), e1226-e1226 (2017).

48. Fiori LM, Turecki G. Implication of the polyamine system in mental disorders. J. Psychiatry Neurosci. 33(2), 102-110 (2008).

49. Chandley MJ, Szebeni A, Szebeni K et al. Elevated gene expression of glutamate receptors in noradrenergic neurons from the locus coeruleus in major depression. Int. J. Neuropsychopharmacol. 17(10), 1569-1578 (2014).

50. Roy B, Yoshino Y, Allen L et al. Exploiting circulating microRNAs as biomarkers in psychiatric disorders. Molec. Diagn. Therap. 24(3), 279-298 (2020).

51. Finnerty JR, Wang WX, Hebert SS et al. The miR-15/107 group of microRNA genes: evolutionary biology, cellular functions, and roles in human diseases. J. Molec. Biol. 402(3), 491-509 (2010).

52. Brites D, Fernandes A. Neuroinflammation and depression: microglia activation, extracellular microvesicles and microRNA dysregulation. Front. Cell. Neurosci. 9, 476 (2015).

53. Qin XY, Wu HT, Cao C et al. A meta-analysis of peripheral blood nerve growth factor levels in patients with schizophrenia. Molec. Psychiatry 22(9), 1306-1312 (2017).

54. Valvezan AJ, Klein PS. Gsk-3 and Wnt signaling in neurogenesis and bipolar disorder. Front. Molec. Neurosci. 5, 1 (2012).

55. Consortium RNConsortium RN, Petrov AI, Kay SJE et al. RNAcentral: an international database of ncRNA sequences. Nucleic Acids Res. 43(Database issue), D123-129 (2015).

56. Bauer ME, Teixeira AL. Inflammation in psychiatric disorders: what comes first? Ann. NY Acad. Sci. 1437(1), 57-67 (2019).

57. Kapinas K, Kessler CB, Delany AM. MiR-29 suppression of osteonectin in osteoblasts: regulation during differentiation and by canonical Wnt signaling. J. Cell. Biochem. 108(1), 216-224 (2009).

58. Brown RAM, Epis MR, Horsham JL et al. Total RNA extraction from tissues for microRNA and target gene expression analysis: not all kits are created equal. BMC Biotechnol. 18(1), 16 (2018).

59. Thery C, Witwer KW, Aikawa E et al. Minimal Information for Studies of Extracellular Vesicles 2018 (MISEV2018): a position statement of the International Society for Extracellular Vesicles and update of the MISEV2014 guidelines. J. Extracell. Vesicles 7(1), 1535750 (2018). 
60. Gao L, Jiang F. MicroRNA (miRNA) profiling. Method. Molec. Biol. 1381, 151-161 (2016).

61. Venigalla H, Mekala HM, Hassan M et al. An update on biomarkers in psychiatric disorders—are we aware, do we use in our clinical practice. Mental Health Fam. Med. 13, 471-479 (2017).

62. Saliminejad K, Khorram Khorshid HR, Ghaffari SH. Why have microRNA biomarkers not been translated from bench to clinic? Future Oncol. 15(8), 801-803 (2019).

63. Van Den Berg MMJ, Krauskopf J, Ramaekers JG, Kleinjans JCS, Prickaerts J, Briede JJ. Circulating microRNAs as potential biomarkers for psychiatric and neurodegenerative disorders. Prog. Neurobiol. 185, 101732 (2020).

64. Backes C, Meese E, Keller A. Specific miRNA disease biomarkers in blood, serum and plasma: challenges and prospects. Molec. Diagn. Ther. 20(6), 509-518 (2016).

65. Ku CS, Cooper DN, Patrinos GP. The rise and rise of exome sequencing. Public Health Genom. 19(6), 315-324 (2016).

66. Pennisi E. Genomics. Encode project writes eulogy for junk DNA. Science. 337(6099), 1159-1161 (2012).

- $\quad$ Paper on noncoding genome database.

67. Griffiths-Jones S, Grocock RJ, Van Dongen S, Bateman A, Enright AJ. MiRbase: MicroRNA sequences, targets and gene nomenclature. Nucleic Acids Res. 34(Database issue), D140-144 (2006).

68. Liu C, Bai B, Skogerbo G et al. NONCODE: an integrated knowledge database of non-coding RNAs. Nucleic Acids Res. 33(Database issue), D112-115 (2005).

69. Jeppesen DK, Fenix AM, Franklin JL et al. Reassessment of exosome composition. Cell 177(2), 428-445 e418 (2019).

70. Roy B, Dwivedi Y. Understanding the neuroepigenetic constituents of suicide brain. Prog. Molec. Biol. Transl. 157, 233-262 (2018). 
